\title{
Theoretical Research on Environmental Evaluation Based on the Perspective of Rural Revitalization
}

\author{
$\mathrm{Li} \mathrm{Li}^{1, *}$, Wan Ajun ${ }^{1}$, and Zhang Zhiang ${ }^{1}$ \\ ${ }^{1}$ New Rural Development Research Institute of Tongji University, Shanghai, China
}

\begin{abstract}
In the process of rural revitalization and development, environmental evaluation plays an important role in nurturing rural planning and construction. Based on the urgent need to realize the intensive and efficient development of China' $\mathrm{s}$ rural areas, this paper studies the rural revitalization system and regional environmental evaluation at home and abroad, and then puts forward a new environmental valueadded evaluation theory, and puts forward ideas for the follow-up study of this topic, aiming to solve the problems faced by the traditional evaluation system in terms of balanced coordination, weight assignment and quantitative embodiment, so as to provide a theoretical basis for the development of new rural planning.
\end{abstract}

\section{Research on Rural Revitalization System}

\subsection{Research on foreign systems}

Generally speaking, the development of rural revitaliZation in foreign countries is mainly promoted from the following aspects. Firstly, rural infrastructure construction is the basic guarantee for development; secondly, in the industrial layout, the local resources and cultural characteristics are fully taken into consideration, and local characteristic industries and surrounding supporting industries are developed; after meeting the basic living and production conditions of the villagers, Fully mobilize and use local villagers as a basis to increase education and supporting service industries to stimulate rural economic development. At the same time of development, the impact on the environment has been fully considered, committed to the layout of environmentally friendly development strategies, and the initial infrastructure construction has been transformed into ecological construction [1]. Taking Britain as an example, the development of its rural system has undergone a four-step transformation of "limit-guidepromote-coordination".
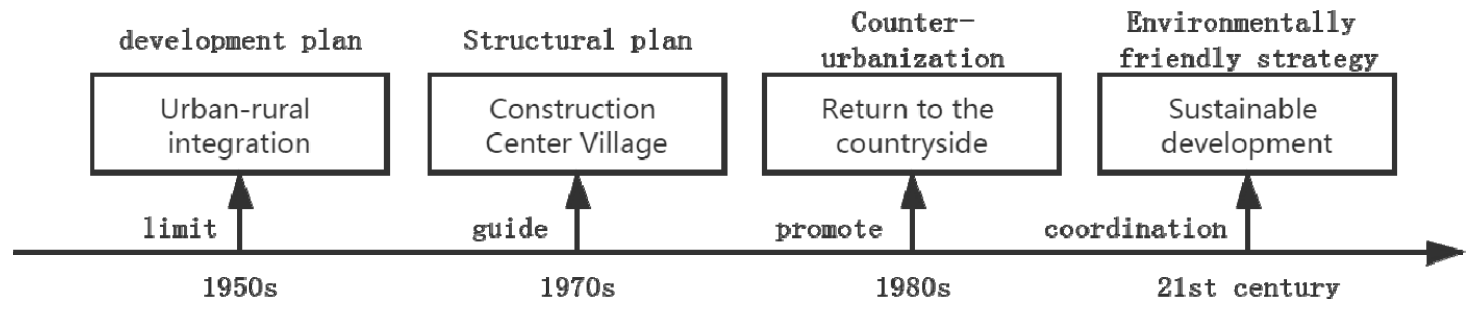

Figure 1. The construction and development of the British rural system

\subsection{Domestic system research}

Compared with developed countries, the research on the rural construction system in china started relatively late. Only in this century has china started to implement the research on new rural construction. After continuous practice and summary by a large number of scholars, china's rural construction has made new developments. Zheng Xiangqun and others analyzed the connotation of beautiful rural construction from three perspectives: the theory of complex ecosystems, the theory of rural multifunctionality, and the theory of sustainable development. The basic idea [2]. Liu Liming and others studied the process of rural urbanization based on ecological principles, and proposed construction measures for the coordinated development of urban and rural areas and the overall layout, so that the rural development model and system ensure its diversity, sustainability, and stability as much as possible, and ultimately achieve harmonious development.

In conclusion, under the strategic background of china's rural revitalization at this stage, many studies have aimed at sustainable development from the beginning, emphasizing development while paying attention to the concept of ecological civilization [3] to ensure the self-development of the later stage of rural

\footnotetext{
* Corresponding author: 1941814@tongji.edu.cn
} 
construction. Therefore, this also requires us to build a scientific quantitative evaluation model for the regional environment, establish a complete evaluation system from the environmental perspective, study and verify the characteristics of the region, and promote the construction of modern agriculture and rural areas in the new era.

\section{Research on regional environmental assessment system}

Regional environmental evaluation is an inevitable product of human socio-economic and productivity development. From the existing research results, domestic and international have provided a rich research theoretical basis for the establishment of ecological civilization index system, as an inspiration and reference, many sustainable development evaluation systems have

Table 1. Regional Environmental Assessment Research and Development

\begin{tabular}{ccc}
\hline \multicolumn{1}{c}{ Argument } & Contribution & Source \\
\hline $\begin{array}{c}\text { Human impact on the global environment } \\
\text { Conduct a biological integrity assessment } \\
\begin{array}{c}\text { Environmental Computing and } \\
\text { Environmental Decision }\end{array}\end{array}$ & $\begin{array}{c}\text { Ecosystem service function concept } \\
\text { The concept of ecosystem sensitivity }\end{array}$ & Carrol MW \\
Our common future & Emergy concept & Karr \\
Pressure-state-response framework model & Sustainable development concept & WCED \\
Our ecological footprint & The model building method & OECD \\
Ecosystem evaluation & The concept of ecological footprint & Rw, E
\end{tabular}

The traditional environmental evaluation system is mainly based on ecological environment evaluation. These methods are basically driven by theory as the core, and study layer by layer from top to bottom, and rarely take into account the balance and coordination of multiple types of elements. From the perspective of research methods, regional environmental evaluation research has produced differentiated evaluation indicators under the guidance of regional characteristics, and the weight of evaluation indicators directly affects the true reliability of the evaluation system. Traditional index weight assignment methods can be divided into two types: function-driven weighting method and difference-driven weighting method. The functiondriven method is usually determined through a subjective approach, and is determined by the degree of impact of indicators on the environmental quality, structure, texture, etc. of the system. Commonly used function-driven methods include analytic hierarchy process and set value iteration method. The differencedriven law emphasizes the influence of the change degree of the index in the system on the system. It is determined based on the law of objective data change. Commonly used difference-driven methods include equal weight method, entropy method, and principal component analysis method. Various weighting methods have their own advantages and disadvantages, and been established. Yan Keng et al. constructed a provincial ecosystem evaluation system from four aspects: environmental quality, social development, ecological vitality, and coordination degree, which quantified and studied the construction of ecological civilization qualitatively and realized the coordinated evaluation of society and nature [4]. Cheng Jinhua et al. constructed a resource-based ecological civilization evaluation system by selecting a total of forty-five indicators from several dimensions, including resource utilization, environmental protection, ecological economy, social development, and green security. Similarly, Li Yue, Liu Lun, Lin Tao, and others have proposed an adapted ecological civilization evaluation system from different perspectives. The development history of specific regional environmental evaluation research is shown in Table 1.

\section{ultimately need to be selected and measured according to} the actual situation of the system.

\section{Environmental value-added evaluation theory}

Based on the difficulties faced by the traditional environmental evaluation system in its application, China's environmental value-added industrial technology innovation strategic alliance came into being, and gave birth to the embryonic form of the environmental valueadded evaluation theory. Environmental value-added takes comfort model[5] and energy flow system as the core, advocates eliminating damage as a whole, planning in advance the ecological integration of human settlements, and carrying out the flow of emergy, assets, and information in a sustainable manner to achieve an overall balanced spiral upward Style development.

\subsection{Environmental comfort information model}

The comfort evaluation reflects the expression of the human body's subjectively comfortable or uncomfortable satisfaction with the external environment, which has an important impact on planning, architectural design, health, tourism, etc. [6]. There are many existing 
models for evaluating environmental comfort, which can be roughly divided into two categories: experience-based models and mechanism-based models. Earlier models were based on experience, using the relevant objective climate environment and corresponding subjective human feelings as the basis for modeling evaluation. Houghton et al. proposed the effective temperature index (ET), which has a profound impact on experience-based models. Subsequently, Vernon et al. replaced the black bulb temperature with dry bulb temperature and thermal radiation, and proposed a modified effective temperature (CET) [6]. Steadman et al. also proposed a real temperature model (AT) [7], which adds the humidity level to the consideration of the human body.

The mechanism-based model is mainly based on the human body heat balance equation [8]. It pays close attention to the physiological and physical mechanisms of the human body, and has received widespread attention after the 1950s. The earliest mechanism comfort evaluation model proposed was the thermal comfort equation of Fanger et al. Afterwards, regression analysis was established through the survey results of thermal sensation, and the predictive evaluation vote number (PMV) was established, which is currently the most widely used thermal comfort evaluation. One of the indicators. Nishi et al. added the skin wetness factor to improve the ET model, called ET*, and then comprehensively considered the thermal resistance of human body activity level and clothing, and proposed the standard effective temperature model (SET) [7].

\subsection{Energy flow analysis system}

According to the conclusions of the ecological circle, the energy theory of the ecological system explains the relationship between the economy and environmental resources of the human society. However, energy analysis cannot intuitively show the relationship between the economic activities of human society and the ecological environment. Based on this dilemma, a new measurement standard was born. The so-called energy value [9] is actually the value of energy contained when one type of energy is transitioned to another type of energy. From a technical point of view, emergy includes the energy of various materials, and any form of energy on the earth comes directly or indirectly from the sun, so solar energy can be used as the benchmark emergy value for measuring different forms of energy. The unit is defined as solar joules. In the process of emergy analysis, with the aid of the evaluation system, the relationship between the ecological environment and the development of human society and economy can be found, so as to better define the operating state and efficiency of the ecosystem, and provide technical support and information decision-making basis for the development of the ecosystem.

In the theory of emergy analysis, the most important part is the concept of emergy conversion rate, which refers to the energy value in a unit of matter and energy, and can also be used as a representative value of solar energy conversion rate [10]. Under different circumstances, any form of energy value comes from solar energy, so the conversion rate can be used as a measure of the relationship between the two. From the perspective of the second law of thermodynamics, when energy is transferred in the food chain, there is often a problem of energy loss, and energy itself has levels. Therefore, in the theory of emergy analysis, when energy goes from a lower level to a higher level During the transition, the conversion of solar energy is also equivalent to the conversion of higher-quality, higherdensity energy. In this process, energy quality and energy levels are increasing. As the emergy conversion rate increases, the energy value of solar energy per unit of energy will increase, and the level of the energy grading system will increase accordingly.

\section{Conclusion}

The theory of environmental value-added evaluation is based on the concept of environmental value-added. Aiming at the dual constraints of rural development and the environment, it establishes a comprehensive and comprehensive value-added evaluation system from the perspectives of ecology, economy, environment, and society to evaluate rural areas. Comprehensive environmental conditions, and further guide the coordinated development of rural areas. Based on this theory, the following requirements are put forward for rural environmental assessment:

(1) The theory of environmental value-added evaluation system

Based on the research of the existing environmental value-added theory and the status quo of rural development in my country, an environmental valueadded evaluation system is constructed, and the valueadded benefits are standardized and quantitatively analyzed on the same scale, and the value-added characteristic factors are extracted to provide new ideas for the development of the rural system.

(2) Environmental comfort information model

Construct a neural network model with an information-driven method to calculate human comfort. Construct a collection of comfort data and objective feature data in the form of questionnaires, and extract the mapping relationship between comfort and the objective environment through nonlinear change mapping of the model to evaluate the regional human comfort index and analyze the region from the perspective of value-added The various influencing factors of comfort are finally combined with actual conditions to establish a planning proposal for optimizing comfort.

(3) Environmental emergy model

Using the theory of emergy analysis, construct a complete emergy analysis map from the perspective of energy circulation, and establish environmental evaluation indicators based on this. The emergy-based indicators are used to construct a value-added evaluation model covering the four levels of resources, space, environmental protection, and development, and finally provide a theoretical basis for planning on the basis of historical data. 


\section{Innovative development ideas}

There are three cycles of material, information, and energy in the rural complex ecosystem. How to build a value-added model from the perspective of information flow and energy flow has become a dilemma facing the development of the current environmental value-added system. Among them: information flow has the characteristics of a large number of, multi-source, unstructured, etc., from the perspective of information analysis of the environment can achieve the purpose of control, optimization, and value-added. When using the advantages of big data for modeling and analysis, we hope to establish an environmental evaluation system On the one hand, it can accurately reflect the local comprehensive environmental conditions, and on the other hand, it can also reflect the contribution of various factors to the internal system. The flow, transfer, and transformation of energy expounds the relationship between economy and resources in the environment, and the indicators in the ecosystem are normalized into emergy units for calculation, which can better compare, measure and optimize the analysis indicators. Therefore, the environmental value-added model based on information flow and energy flow will comprehensively evaluate rural development and rural environment, and coordinate rural ecological and economic development.

\section{References}

1. Rw E. (1997) Our ecological footprint. Green Teacher, 45: 5-14.

2. Zheng X, Chen M. (2015) Theoretical framework and model design of beautiful rural construction in my country. Journal of Agricultural Resources and Environment, 2: 106-115.

3. Lin T, Ge R, Huang J, et al. (2016) A quantitative method to assess the ecological indicator system's effectiveness: a case study of the ecological province construction indicators of china. Ecological indicators, 62: 95-100.

4. Yan G, Lin Z, Wu M. (2013) Progress and evaluation of China's provincial ecological civilization construction. Chinese Administration, 10: 7-12.

5. Salata F, Golasi I, et al. (2017) Implications of climate and outdoor thermal comfort on tourism: the case of italy. International Journal of Biometeorology, 12.

6. Sun M, Li S. (2015) The empirical model of climate comfort evaluation: review and outlook. Tourism Tribune, 12: 19-34.

7. Zhang F. (2015) Research on the Numerical Evaluation Index System of Tourism Climate Comfort. Geography Teaching, 18: 4-11.

8. Negin, Nazarian, Jipeng, et al. (2017) Predicting outdoor thermal comfort in urban environments: A 3D numerical model for standard effective temperature. Urban Climate, 20.

9. Liu Z, Wang Y, Wang S, et al. (2018) An Emergy and Decomposition Assessment of China's Crop Production: Sustainability and Driving Forces. Sustainability, 11.

10. Lu H, Tan Y W, Zhang W, et al. (2017) Integrated emergy and economic evaluation of lotus-root production systems on reclaimed wetlands surrounding the Pearl River Estuary, China. Journal of Cleaner Production, 158: 367-379. 